\title{
TO EVALUATE THE HAEMODYNAMIC EFFECTS OF ETOMIDATE AND A COMBINATION OF ETOMIDATE AND PROPOFOL AS INDUCTION AGENTS IN ELECTIVE SURGERIES
}

\author{
Anisha Puri', Manisha Bhatt Dwivedi2, Pranav Arora ${ }^{3}$, Divya Vijay ${ }^{4}$
}

1Assistant Professor, Department of Anaesthesia, Maharishi Markandeshwar Institute of Medical Sciences, Mullana, Haryana, India. 2Professor and HOD, Department of Anaesthesia, Maharishi Markandeshwar Institute of Medical Sciences, Mullana, Haryana, India. ${ }^{3} 3^{\text {rd }}$ Year Resident, Department of Anaesthesia, Maharishi Markandeshwar Institute of Medical Sciences, Mullana, Haryana, India.

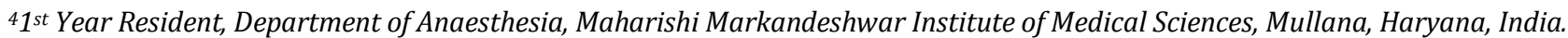
ABSTRACT

\section{BACKGROUND}

Haemodynamic changes during laryngoscopy and intubation are the major concern during induction under general anaesthesia. Our study aims to compare the haemodynamic changes between etomidate versus a combination of etomidate and propofol.

\section{MATERIALS AND METHODS}

Sixty patients in age group of 18-50 years of ASA grade I and II were divided randomly into two groups of thirty patients each. Haemodynamic data was observed and compared. Sample size was taken for convenience.

\section{RESULTS}

Statistically significant difference was found in heart rate ( $p=0.000$ at induction; $p=0.0001$ at 1 min after intubation) and MAP in both the groups at 0 min $(\mathrm{p}=0.0008)$ and after 1 minute $(\mathrm{p}=0.004)$ of induction with haemodynamic parameters significantly higher in etomidate group than the etofol group. There was no statistically significant difference at 2 mins, 5 mins, 10 mins, 20 mins, 30 mins and 60 mins between the two groups.

\section{CONCLUSION}

The combination of etomidate and propofol is an alternative to etomidate alone in patients where laryngoscopic response to haemodynamic parameters is a concern.

\section{KEY WORDS}

Haemodynamic, Induction, Propofol, Etomidate

HOW TO CITE THIS ARTICLE: Puri A, Dwivedi MB, Arora P, et al. To evaluate the haemodynamic effects of etomidate and a combination of etomidate and propofol as induction agents in elective surgeries. J. Evolution Med. Dent. Sci. 2019;8(09):555-558, DOI: $10.14260 /$ jemds/2019/123

\section{BACKGROUND}

Haemodynamic stability during laryngoscopy and intubation with minimal side effects is the main objective of any anaesthetist. Pressor response to laryngoscopy is due to receptors present at the tongue base that get stimulated, catecholamines rise in levels of adrenaline and noradrenaline, stimulation of the laryngeal and tracheal receptors. The arterial pressure may rise to $20-25 \mathrm{mmHg}$ and peak is usually seen 30-35 seconds after laryngoscopy. On one hand, laryngoscopy leads to sympathetic responses leading to tachyarrhythmias and hypertension ${ }^{1}$ increased intracranial tension and greater myocardial workload. On the other hand, induction agents cause vasodilation and obliteration of autonomic nervous system leading to hypotension. 2,3

A single induction agent may cause haemodynamic changes. ${ }^{4}$ Propofol is the most commonly induction agent due to its fast action and short time of action. But anaesthesia using propofol as induction agent lead to hypotension, bradycardia. 5,6

'Financial or Other Competing Interest': None.

Submission 01-02-2019, Peer Review 20-02-2019,

Acceptance 22-02-2019, Published 04-03-2019.

Corresponding Author:

Dr. Manisha Bhatt Dwivedi,

Department of Anaesthesia,

Maharishi Markandeshwar Institute of Medical Sciences,

Mullana, Haryana, India.

E-mail: manishabhattdwivedi@gmail.com

DOI: $10.14260 /$ jemds $/ 2019 / 123$

\section{(c) $($ i) $\odot$}

Etomidate is relatively cardio stable without any histamine release, but it causes Injection pain, thrombophlebitis and huge incidence of emesis. Etomidate also does not satisfactorily attenuate sympathetic laryngoscopic responses.7,8 and has been known to occasionally cause ventricular tachycardia and fibrillation. ${ }^{9}$

Such haemodynamic changes are well tolerated in normal individuals but may be life threatening in cardiac patients and patients of increased intracranial pressue.

We took this study to know if the haemodynamic changes after laryngoscopy and intubation can be decreased by decreasing the doses of etomidate and propofol together. Hence, we studied the difference in haemodynamic changes by comparing etomidate with a combination of etomidate and propofol (etofol).
Aim of The Study
To evaluate and compare the efficacy of etomidate and etofol as induction agents in maintaining haemodynamic stability in elective surgery under general anaesthesia.

\section{MATERIALS AND METHODS}
This non randomized control trial study was conducted in the department of anaesthesiology Maharishi Markandeshwar institute of medical sciences and research Mullana, after approval from Institutional Ethical Committee, 60 patients aged 18 to 50 years of ASA grading I and II scheduled for elective surgery of $2 \mathrm{hrs}$., duration general anaesthesia were taken and divided into two groups. Hypertensive, diabetic, epileptics and pregnant patients and patients with 
hepatorenal and respiratory diseases were excluded from our study. Sample size was taken for convenience.

Baseline heart rate (Preoperative), systolic blood pressure (SBP), diastolic blood pressure (DBP), mean blood pressure (MBP) and oxygen saturation (SPO2) and end tidal carbon dioxide (ETCO2) were noted.

Anaesthesiologist who was blinded to the study monitored and recorded Heart rate, systolic blood pressure, diastolic blood pressure, mean arterial blood pressure and oxygen saturation before induction and after induction at 1 minute, 2 minute, 5 minutes, 10 minutes, 20 minutes, 30 minutes, 60 minute.

\section{Statistical Analysis}

Mean and standard deviations of all the parameters were calculated out. Statistical analysis was done using SPSSVersion 21. Unpaired ' $t$ ' test was done to calculate the $p$-value ( $p<0.05$ was considered significant).

\section{RESULTS}

This non randomized control trial study was carried out on 60 patients between the age group 18-50 years at MMIMSR, Mullana to evaluate the hemodynamic effects of etomidate and etofol as induction agent in elective surgeries.

\begin{tabular}{|c|c|c|c|c|}
\hline Variable & Group I & Group II & p Value & $\begin{array}{c}\text { Statistical } \\
\text { Significance }\end{array}$ \\
\hline Age & $\begin{array}{c}37.60 \pm \\
9.64\end{array}$ & $\begin{array}{c}37.62 \pm \\
9.06\end{array}$ & 0.265 & NS \\
\hline Sex (M/F) & $18 / 12$ & $28 / 10$ & 0.279 & NS \\
\hline Weight (kg) & $57.5 \pm 1.6$ & $58.1 \pm 1.8$ & 0.232 & NS \\
\hline \multicolumn{5}{|c|}{ Table 1. Demographic Data } \\
\hline
\end{tabular}

There was no statistically significant difference in the demographic data of the two groups with respect to age, sex and weight.

\begin{tabular}{|c|c|c|c|}
\hline Time & Group I & Group II & p Value \\
\hline Baseline & $84.5 \pm 9.8$ & $81.2 \pm 11.8$ & 0.255 \\
\hline At 0 Minute & $86.7 \pm 8.3$ & $75.8 \pm 9.2$ & $0.000^{\mathrm{s}}$ \\
\hline At 1 Minute & $84.8 \pm 8.7$ & $74.4 \pm 9.1$ & $0.0001^{\mathrm{s}}$ \\
\hline At 2 Minutes & $80.8 \pm 10.2$ & $78.7 \pm 8.3$ & $0.372^{\mathrm{NS}}$ \\
\hline At 5 Minutes & $79.6 \pm 9.6$ & $76.5 \pm 7.8$ & $0.167^{\mathrm{NS}}$ \\
\hline At 10 Minutes & $78.4 \pm 9.2$ & $75.5 \pm 7.6$ & $0.219^{\mathrm{NS}}$ \\
\hline At 30 Minutes & $78.5 \pm 10.5$ & $74.9 \pm 7.4$ & $0.154 \mathrm{NS}$ \\
\hline At 60 Minutes & $78.5 \pm 10.0$ & $74.3 \pm 7.5$ & $0.079^{\mathrm{NS}}$ \\
\hline \multicolumn{4}{|c|}{ Table 2. Heart Rate } \\
\hline
\end{tabular}

There was no statistically significant difference in the demographic data of the two groups with respect to age, sex and weight.

\begin{tabular}{|c|c|c|c|}
\hline Time & Group I & Group II & p Value \\
\hline Baseline & $102.1 \pm 4.9$ & $103 . \pm 4.4$ & $0.213^{\mathrm{NS}}$ \\
\hline At 0 Minute & $103 \pm 6.8$ & $97.3 \pm 5.6$ & $0.0008^{*}$ \\
\hline At 1 Minute & $94.4 \pm 6.4$ & $92.1 \pm 7.4$ & $0.004^{*}$ \\
\hline At 2 Minutes & $96.0 \pm 8.2$ & $97.4 \pm 4.4$ & $0.379^{\mathrm{NS}}$ \\
\hline At 5 Minutes & $95.2 \pm 6.8$ & $96.1 \pm 4.5$ & $0.536^{\mathrm{NS}}$ \\
\hline At 10 Minutes & $94.6 \pm 5.6$ & $95.7 \pm 3.5$ & $0.359^{\mathrm{NS}}$ \\
\hline At 30 Minutes & $95.1 \pm 6.1$ & $95.6 \pm 5.4$ & $0.722^{\mathrm{NS}}$ \\
\hline At 60 Minutes & $95.3 \pm 5.8$ & $96.0 \pm 4.7$ & $0.612^{\mathrm{NS}}$ \\
\hline \multicolumn{4}{|c|}{ Table 3. Mean Blood Pressure } \\
\hline
\end{tabular}

As evident from the table the baseline heart rate was comparable among the groups. Mean HR in Group I was 84.5 \pm 9.8 and in group II was $81.2 \pm 11.8$. Tachycardia was seen in group I at 0 minute $(p=0.000)$ and at 1 minute $(p=0.0001)$ as compared to baseline. This was statistically significant when compared to group II. But there was marginal increase in heart rate from the baseline and did not require any clinical intervention.

Mean baseline MBP in Group I was $102.1 \pm 4.9$ in group II was103.6 \pm 4.4 . Tachycardia was seen in group I at 0 minute $(p=0.000)$ and at 1 minute $(p=0.0001)$ as compared to baseline. This was statistically significant when compared to group II. But there was marginal increase in heart rate from the baseline and did not require any clinical intervention.

\section{DISCUSSION}

Endotracheal intubation may lead to sympathetic effects like dysrhythmia, hypertension, myocardial ischemia, infarction, hypoxia, hypercapnia, laryngospasm, bronchospasm, raised intraocular and intracranial pressure. Such haemodynamic changes are well tolerated in normal individuals but may be life threatening in cardiac patients and may lead to complications like stroke, ischaemia, myocardial infarction and even death. There has been search of an ideal induction agent that is haemodynamically stable during laryngoscopy and without side effects since the advent of anaesthesia. ${ }^{10}$

Thiopentone, Etomidate, Propofol, Midazolam, and Ketamine are the commonly used induction agents. ${ }^{11,12}$ There are concerns regarding smooth induction and emergence from anaesthesia with thiopentone, midazolam and ketamine. ${ }^{13}$ Propofol and Etomidate have emerged as the preferred induction agents. ${ }^{14,15}$

Propofol has a fast and smooth induction with reduced chance of emesis.16,17 Propofol leads to haemodynamic instablity as it decreases systemic vascular resistance causing hypotension. ${ }^{9}$ It also leads to respiratory depression and pain on injection. 18,19

Etomidate is devoid of any effect on sympathetic nervous system or baroreceptor regulatory system and causes minimal respiratory depression. ${ }^{20,21}$ It acts on peripheral alpha-2B adrenergic receptors causing vasoconstriction. ${ }^{22}$ But increased chance of emesis which may cause aspiration, myoclonus, thrombophlebitis and adrenal insufficiency with

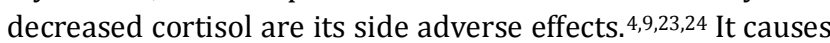
reversible inhibition of 11- $\beta$-hydroxylase, hence preventing the conversion of 11-deoxy cortisol to cortisol. Single-dose etomidate inhibits 11- $\beta$-hydroxylase in 5-8 hours postoperatively. Also, it does not effectively blunt the sympathetic response to laryngoscopy leading to increased intracranial tension and increased myocardial workload. It also may cause ventricular tachycardia and fibrillation may be seen. ${ }^{9}$

Neither propofol nor etomidate is the preferred induction agent for hypertensives, elderly patients and patients of ASAIII and IV or MAP $<70 \mathrm{mmHg}$. If etomidate is used in such patients, it also does not blunt laryngoscopic sympathetic response.

In view of the above adverse effects of the two drugs used individually, we used a combination of propofol, and etomidate called Etofol where we reduced the dose of Etomidate $(0.15 \mathrm{mg} / \mathrm{kg})$ and propofol $(1 \mathrm{mg} / \mathrm{kg})$ and compared its haemodynamic effects with $0.3 \mathrm{mg} / \mathrm{kg}$ etomidate. We took both the drugs under strict aseptic conditions in separate injectors as done by Yagan 0 et al ${ }^{8}$ as 
infection has been reported with propofol contamination. ${ }^{25,26}$ At the time when Yagan et al published their study, they quoted that apart from their study, only 3 studies are done previously using etofol as induction agent. ${ }^{8}$ With etofol, dose of both the drugs is decreased to half of their individual higher doses. Taking combination of both the drugs aims at better haemodynamic stability and induction with decreased incidence of pain on injection and myoclonus. ${ }^{8}$

Combination of different induction agents has been used in the past which cause an evident decrease in anaesthetic, better sedation and amnesia, decreased side effects and reduce cost. 10

Demographic profile with respect to age, sex and weight were comparable in both the groups and consistent with the study by K Meena et al with age group ( $p=0.178)$ and gender distribution $(\mathrm{p}=0.241)$. $^{2}$

Statistically significant difference was found in heart rate, SBP, DBP and MAP in both the groups at 0 min and after 1 minute of induction with hemodynamic parameters significantly higher in etomidate group than the etofol group but did not require any clinical intervention. There was no statistically significant difference at $2 \mathrm{~min}, 5 \mathrm{~min}, 10 \mathrm{~min}$, $20 \mathrm{~min}, 30 \mathrm{~min}$ and 60 minutes between the two groups

Similar results seen by Yağan Ö et al support our study. ${ }^{8}$ Our findings are also consistent with the study done by Hosseinzadeh who found the etofol to be more haemodynamically stable as compared to the etomidate alone. ${ }^{27}$

Muriel et al compared propofol, thiopental and etomidate and found a statistically significant increase in systolic and diastolic arterial pressure and HR in the etomidate group after intubation. Möller et al compared propofol and etomidate where Propofol group showed a statistically significant hypotension while statistically significant hypertension was seen in the etomidate group. Compared with etomidate, the use of propofol was determined to have caused less hypertension and tachycardia after intubation. ${ }^{28}$

Weiss Bloom LJ et al. postulated that addition of fentanyl 5-10 mcg $\mathrm{kg}-1$ to etomidate is needed to avoid haemodynamic laryngoscopic response. But such a high dose of fentanyl leads to hypotension and nausea and vomiting. Etofol may also decrease requirement of opioids like fentanyl.

Earlier studies have compared the haemodynamic changes only during induction. Saricaoglu et al. compared haemodynamic changes of propofol, etomidate and etofol only during anaesthesia induction. ${ }^{2}$ Hosseinzadeh et al compared haemodynamic changes of propofol, etomidate and etofol during LMA insertion. ${ }^{27}$ Our study compared etofol with etomidate and, not only during anaesthesia induction but after tracheal intubation.

\section{CONCLUSION}

Combination of etomidate and propofol is an alternative to etomidate alone in patients where laryngoscopic response to haemodynamic parameters is a concern.

\section{REFERENCES}

[1] Creagh O, Torres H, Rodríguez N, et al. Alpha-2B adrenergic receptor mediated hemodynamic profile of etomidate. P R Health Sci J 2010;29(2):91-5.
[2] Saricaoglu F, Uzun S, Arun O, et al. A clinical comparison of etomidate-lipuro, propofol and admixture at induction. Saudi J Anaesth 2011;5(1):626.

[3] Weisenberg M, Sessler DI, Tavdi M, et al. Dosedependent hemodynamic effects of propofol induction following brotizolam premedication in hypertensive patients taking angiotensin-converting enzyme inhibitors. J Clin Anesth 2010;22(3):190-5.

[4] Lim YS, Kang DH, Kim SH, et al. The cardiovascular effects of midazolam co-induction to propofol for induction in aged patients. Korean J Anesthesiol 2012;62(6):536-42.

[5] Reves JG, Glass PSA, Lubarsky DA, et al. Intravenous nonopioid anesthetics. In: Miller RD, edr. Miller's Anesthesia. $6^{\text {th }}$ edn. Philadelphia: Churchill Livingstone 2005: p. 317-78.

[6] Canbay O, Celebi N, Arun O, et al. Efficacy of intravenous acetaminophen and lidocaine on propofol injection pain. Br J Anaesth 2008;100(1):95-8.

[7] Güzelmeriç F, Erdoğan HB, Koçak T. Kardiyak acillerde anestezik yaklaşım. Türk Göğüs Kalp Damar Cer Derg 2007;15(1):82-9.

[8] Yağan Ö, Taş N, Küçük A, et al. Haemodynamic responses to tracheal intubation using propofol, etomidate and etomidate-propofol combination in anaesthesia induction. J Cardiovasc Thorac Res 2015;7(4):134-40.

[9] Karcioglu M, Davarci I, Kirecci N, et al. The development of ventricular fibrillation due to etomidate for anesthetic induction: a very rare side effect, case report. Rev Braz J Anesthesiol 2014;64(5):365-8.

[10] Meena K, Meena R, Nayak SS, et al. A comparative study of effect of propofol, etomidate and propofol plus etomidate induction on hemodynamic response to endotracheal intubation: A RCT. J Anesth \& Clin Res 2016;7:622.

[11] Singh R, Choudhury M, Kapoor PM, et al. A randomized trial of anesthetic induction agents in patients with coronary artery disease and left ventricular dysfunction. Ann Card Anaesth 2010;13(3):217-23.

[12] Stowe DF, Bosnjak ZJ, Kampine JP. Comparison of etomidate, ketamine, midazolam, propofol and thiopental on function and metabolism of isolated hearts. Anesth Analg 1992;74(4):547-58.

[13] Kaushal RP, Vatal A, Pathak R. Effect of etomidate and propofol induction on hemodynamic and endocrine response in patients undergoing coronary artery bypass grafting/mitral valve and aortic valve replacement surgery on cardiopulmonary bypass. Ann Card Anaesth 2015;18(2):172-8.

[14] Bendel S, Ruokonen E, Pölönen P, et al. Propofol causes more hypotension than etomidate in patients with severe aortic stenosis: a double-blind, randomized study comparing propofol and etomidate. Acta Anaesthesiol Scand 2007;51(3):284-9.

[15] Hosten T, Solak M, Kilickan L, et al. The effects of etomidate and propofol induction on hemodynamic and endocrine responses in patients undergoing CABG surgery. Balkan Med J 2007;24:114-26. 
[16] Aggarwal S, Goyal VK, Chaturvedi SK, et al. A comparative study between propofol and etomidate in patients under general anesthesia. Brazilian Journal of Anesthesiology 2016;66(3):237-41.

[17] Shinn HK, Lee MH, Moon SY, et al. Post-operative nausea and vomiting after gynecologic laparoscopic surgery: comparison between propofol and sevoflurane. Korean J Anesthesiol 2011;60(1):36-40.

[18] Maruyama K, Nishikawa Y, Nakagawa H, et al. Can intravenous atropine prevent bradycardia and hypotension during induction of total intravenous anesthesia with propofol and remifentanil? J Anesth 2010;24(2):293-6.

[19] Ozgul U, Begec Z, Erdogan MA, et al. Effect of alkalinisation of lignocaine for propofol injection pain: a prospective, randomised, double-blind study. Anaesth Intensive Care 2013;41(4):501-4.

[20] Wu J, Yao S, Wu Z, et al. A comparison of anesthetic regimens using etomidate and propofol in patients undergoing first-trimester abortions: double-blind, randomized clinical trial of safety and efficacy. Contraception 2013;87(1):55-62.

[21] Kalogridaki M, Souvatzis X, Mavrakis HE, et al. Anaesthesia for cardioversion: a prospective randomised comparison of propofol and etomidate combined with fentanyl. Hellenic J Cardiol 2011;52(6):483-8.

[22] Shah SB, Chowdhury I, Bhargava AK, et al. Comparison of hemodynamic effects of intravenous etomidate versus propofol during induction and intubation using entropy guided hypnosis levels. Journal of Anaesthesiology, Clinical Pharmacology 2015;31 (2):180-5.
[23] Morel J, Salard M, Castelain C, et al. Haemodynamic consequences of etomidate administration in elective cardiac surgery: a randomized double-blinded study. Br J Anaesth 2011;107(4):503-9.

[24] Kim TK, Park IS. Comparative study of brain protection effect between thiopental and etomidate using bispectral index during temporary arterial occlusion. J Korean Neurosurg Soc 2011;50(6):497502.

[25] McNeil MM, Lasker BA, Lott T], et al. Postsurgical Candida albicans infections associated with an extrinsically contaminated intravenous anesthetic agent. J Clin Microbiol 1999;37(5):1398-403.

[26] Klein J, Huisman I, Menon AG, et al. Postoperative infection due to contaminated propofol. Ned Tijdschr Geneeskd 2010;154:A767.

[27] Hosseinzadeh H, Golzari SEJ, Torabi E, et al. Hemodynamic changes following anesthesia induction and LMA insertion with propofol, etomidate and propofol + etomidate. J Cardiovasc Thorac Res 2013;5(3):109-12.

[28] Petrun MA, Kamenik M. Bispectral index-guided induction of general anaesthesia in patients undergoing major abdominal surgery using propofol or etomidate: a double-blind, randomized, clinical trial. Br J Anaesth 2013;110(3):388-96. 